\title{
Genetic Variation for Biomass and Related Morphological Traits in Cup Plant (Silphium perfoliatum L.)
}

\author{
Teshale Assefa1, Jixiang Wu ${ }^{1}$, Kenneth A. Albrecht' ${ }^{2}$, Paul J. Johnson ${ }^{1}$, Arvid Boe ${ }^{\text {* }}$ \\ ${ }^{1}$ Plant Science Department, South Dakota State University, Brookings, SD, USA \\ ${ }^{2}$ Department of Agronomy, University of Wisconsin-Madison, Madison, WI, USA \\ Email: tmamo@iastate.edu, jixiang.wu@sdstate.edu, kaalbrecht@wisc.edu, paul.johnson@sdstate.edu, \\ *arvid.boe@sdstate.edu
}

Received 1 April 2015; accepted 8 May 2015; published 11 May 2015

Copyright (C) 2015 by authors and Scientific Research Publishing Inc.

This work is licensed under the Creative Commons Attribution International License (CC BY).

http://creativecommons.org/licenses/by/4.0/

c) (i) Open Access

\section{Abstract}

Cup plant (Silphium perfoliatum L.) has demonstrated potential for bioenergy production in North America, South America, and Europe. Our objectives were to: 1) determine genetic variation and narrow-sense heritability for biomass and related morphological traits, and 2) identify half-sib families with superior biomass yield and potential for use in cultivar development in cup plant. Thirty three half-sib families and a check were evaluated at two locations in 2011, 2012, and 2013.

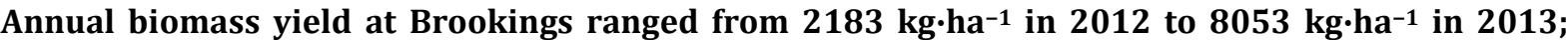
whereas, yields at Arlington were similar among years. Mean individual half-sib family biomass yield ranged from 3912 to $6784 \mathrm{~kg} \cdot \mathrm{ha}^{-1}$ at Brookings and from 5682 to $11,269 \mathrm{~kg}^{-\mathrm{ha}^{-1}}$ at Arlington. Heritability estimates for five biomass-related morphological traits ranged from 0.52 to 0.72 . This cup plant population had potential for biomass production in the north central USA and contained sufficient additive genetic variation to expect progress from among-and-within-family selection for biomass yield and related traits.

\section{Keywords}

Cup Plant, Half-Sib Families, Heritability

\section{Introduction}

Cup plant (Silphium perfoliatum L.) is a tall and vigorous diploid ( $\mathrm{n}=7$ ) member of the Heliantheae tribe of the Asteraceae family. It is native to the eastern one-half of the USA and Canada, growing in moist ground from

\footnotetext{
*Corresponding author.

How to cite this paper: Assefa, T. Wu, J.X., Albrecht, K.A., Johnson, P.J. and Boe, A. (2015) Genetic Variation for Biomass and Related Morphological Traits in Cup Plant (Silphium perfoliatum L.). American Journal of Plant Sciences, 6, $1098-1108$. http://dx.doi.org/10.4236/ajps.2015.68114
} 
southern Ontario to North Carolina and west to the Great Plains and Arkansas [1]. It is a long-lived perennial, can exceed $2 \mathrm{~m}$ in height, and has shoots that arise from short rhizomes on a broad woody crown [2]. It differs from other species in the genus Silphium by its opposite pairs of cup forming leaves [3]. In the northern Great Plains, it is rare in the eastern Dakotas in lowland prairies and open woodlands [2] [4]. Because of its excellent winter-hardiness and tolerance of poorly drained soils cup plant can serve as an alternative to alfalfa (Medicago sativa L.) on soils that tend to flood in the spring; and an alternative to corn (Zea mays L.) for silage on soils that are too wet to plant in the spring [5]-[7].

Cup plant was likely introduced to Europe in the $18^{\text {th }}$ century as an ornamental [8] and to Russia in the 1950 s as a forage crop [3]. It is currently used in Europe [8] [9], South America [10], and Asia [11] for forage, bioenergy, and phytoremediation [12]. A recent study in Germany determined cup plant had potential for bioenergy production on marginal land because of its high water use efficiency and adaptation to low input agricultural practices [13]. In China, where it was introduced in the 1980s and was widely used for fodder for cattle, swine and rabbits, cup plant had higher water use efficiency and crude protein yield than alfalfa under normal and wet climatic conditions [11].

Biomass yields of cup plant have approached $20 \mathrm{Mg} \mathrm{ha}^{-1}$ in Europe [9] and exceeded $20 \mathrm{Mg} \mathrm{ha}^{-1}$ in Chile [7] [10] and in Wisconsin in the USA (K. Albrecht, unpublished data). Cup plant, because it is well adapted to low, moist prairies which are not suitable for conventional perennial crops, such as alfalfa, (Boe, unpublished data), could be an excellent complementary species to grow in mixtures with perennial grasses for biofuel [14]. A recent review article concluded that cup plant was a very promising crop for biogas production throughout Europe due to its high biomass yield, stand longevity, and usefulness for erosion control on marginal land [8]. However, the authors pointed out that development of new cultivars, optimization of harvest timing, identification of potential disease and insect pests, and development of effective for rapid stand establishment from seed were areas of needed research.

Presently the emphasis for perennial herbaceous bioenergy crop breeding and cultivar development is on native C4 grasses such as switchgrass (Panicum virgatum L.) [15] and prairie cordgrass (Spartina pectinata Link) [16], introduced C4 grasses, primarily Miscanthus (Miscanthusx giganteus) [17], and to a lesser extent alfalfa (Medicago sativa L.) for use in sustainable perennial herbaceous bioenergy production systems [18]. However, there is a need to identify populations of native North American forbs that: 1) are adapted to and provide environmental benefits on marginal cropland, 2) produce high amounts of biomass in sustainable perennial herbaceous bioenergy production systems with grasses, and 3) increase biodiversity and pollinator habitat in herbaceous bioenergy production systems. Recently, cup plant has been identified as promising for those and other economic and environmental purposes in Europe [9] [13] and the northern Great Plains in the USA [19].

Albrecht and Goldstein (1997) determined there was genetic variation among natural populations of cup plant from the Midwest for forage production and quality. Natural populations from Illinois and Minnesota were superior to a population from Russia (original North American source unknown) for yield and crude protein. In a second experiment they evaluated the aforementioned three populations and 25 natural populations from Wisconsin for three years at three locations. Significant differences occurred among populations for forage yield and quality and populations ranked similarly across locations. These results led Albrecht and Goldstein to conclude that superior natural populations could serve as valuable sources of among-population genetic variation for cultivar development. However, to date there are no detailed studies of within-population genetic variation for biomass production and related morphological traits for cup plant adapted to the northern Great Plains and Midwest regions of the USA.

Therefore, objectives of the present study on cup plant were to: 1) measure within-population genetic variation and estimate narrow-sense heritability for biomass and biomass-related morphological traits, 2) determine strength of genetic correlations among said traits, 3) develop a strategy for cultivar development for bioenergy and conservation purposes, 4) collect descriptive information on life histories of insects of cup plant that may become pests in agronomic settings, and 5) identify any parasitoids or other natural enemies that have potential for biological control.

\section{Materials and Methods}

First, field experiments were conducted over a three-year period (2011-2013) in South Dakota and Wisconsin. The experiment in South Dakota was on the South Dakota State University Experimental Station Felt Farm near 
Brookings, SD $\left(44^{\circ} 19^{\prime} \mathrm{N}\right.$ and $\left.96^{\circ} 42^{\prime} \mathrm{W}\right)$. The soil was a McInotsh (fine-silty, mixed, superactive, frigid aquiccaldiudolls)-Badger (fine, smectitic, frigid verticargiaquolls) silty clay loam. Precipitation data for each of the growing seasons for 2011, 2012, and 2013 at Brookings are presented in Table 1. The experimental site in Wisconsin was on the University of Wisconsin-Madison College of Agricultural \& Life Sciences Agricultural Research Station soil at Arlington $\left(43^{\circ} 34^{\prime} \mathrm{N}\right.$ and $\left.89^{\circ} 38^{\prime} \mathrm{W}\right)$ where the soil type was a Plano silt loam (fine-silty, mixed, superactive, mesic, typic, argiudolls).

The cup plant population used for this genetic study was composed of progenies of 33 parent plants derived from bulk seed produced by putative random mating among several plants from each of natural populations from Minnesota and Illinois (seed was obtained from Dr. Walter Goldstein, Michael Fields Institute, East Troy, WI) in a spaced plant nursery at Brookings, SD. The natural populations from IL and MN [5] had shown potential for forage production on poorly-drained marginal land in South Dakota and Wisconsin. Seeds of the 33 half-sib families (coded here as F1-F33) were produced in an isolated polycross nursery at Brookings. A "check" population developed by K. Albrecht from open pollination of 26 natural populations from Wisconsin, Illinois, Iowa, and Minnesota and previously evaluated in forage production and dairy cattle (Bos taurus L.) feeding trials in Wisconsin was included for comparison to the half-sib families at both Brookings and Arlington. In addition, a hybrid population developed by K. Albrecht from a cross between natural populations from Wisconsin and Arkansas was included in the experiment at Arlington.

From seeds planted in the greenhouse, seedlings from the 33 half-sib families and the "check" and hybrid populations that were grown for three months in cone-tainers (Stuewe, Inc., Corvallis, OR) in the greenhouse were transplanted to the field sites in June 2010 in randomized complete block designs with three replicates at Brookings and Arlington. At Brookings, individual plots were single rows composed of six plants with $0.9 \mathrm{~m}$ between rows and $0.4 \mathrm{~m}$ between plants within rows. At Arlington, individual plots were rows of seven plants with $1.0 \mathrm{~m}$ inter- and intra-row spacing. At Brookings, the four interior plants of each 6-plant plot were hand harvested with a rice knife at a stubble height of $10 \mathrm{~cm}$ during late September 2011, 2012 and 2013. Fresh weight was taken in the field at harvest. Grab samples were dried at $60^{\circ} \mathrm{C}$ for 72 hours for determination of dry matter concentration.

For each of the four centrally located plants, crown area (estimated from the average of diameter measurements taken in each of North-South and East-West directions at mid height) and internodes shoot ${ }^{-1}$ were taken at first flower while plant height was taken at full bloom. Mass shoot ${ }^{-1}$ for each plot was determined from biomass yield and shoots plot ${ }^{-1}$. Shoots $\mathrm{m}-2$ was also determined from shoots plot $^{-1}$. These morphological traits were chosen as individual-plant vigor metrics that would be expected to have positive genetic correlations with biomass yield and would provide data necessary for within-family selection to augment among-family selection from plot-based biomass yield [20].

Biomass yield was the only trait measured at Arlington. Plots were harvested with a flail chopper at a stubble height of $10 \mathrm{~cm}$ during September in each of 2011, 2012, and 2013. Fresh weights were recorded in the field and dry matter concentrations were determined as described for Brookings.

Weed control was as needed by hand at both Brookings and Arlington during 2010 through 2013. Fertilizer was not applied during 2010-2012 at Brookings. In May 2013 at Brookings, $90 \mathrm{~kg} \cdot \mathrm{N} \cdot \mathrm{ha}^{-1}$ were broadcasted. At Arlington, $120 \mathrm{~kg} \cdot \mathrm{N} \cdot \mathrm{ha}^{-1}$ were broadcasted during late April in each of 2010 through 2013.

The experiment at Brookings was evaluated weekly during July through August in each of 2011, 2012, and 2013 to monitor the impact of larvae of the cup plant moth (Eucosma giganteana Riley) and adults and nymphs

Table 1. Precipitation totals (mm) during the growing seasons of 2010, 2011, 2012, and 2013 at Brookings, South Dakota ${ }^{1}$.

\begin{tabular}{|c|c|c|c|c|c|c|}
\hline \multirow[b]{2}{*}{ Year } & \multicolumn{6}{|c|}{ Month } \\
\hline & April & May & June & July & August & September \\
\hline 2010 & 31 & 56 & 202 & 134 & 121 & 188 \\
\hline 2011 & 33 & 111 & 85 & 106 & 34 & 2 \\
\hline 2012 & 59 & 161 & 43 & 31 & 50 & 11 \\
\hline 2013 & 34 & 66 & 125 & 81 & 36 & 36 \\
\hline
\end{tabular}

${ }^{1}$ South Dakota Climate and Weather (http://climate.sdstate.edu/climate_site/archive_data.html). 
of the cup plant aphid [Uroleucon rudbeckiae (Fitch)], when either were present, on growth and development of the half-sib families. During those evaluations, attention was also paid to collection, identification, and determination of the frequency of parasitism of the aphids by parasitoids belonging to Hymenoptera. Estimates of frequency of floral meristem destruction by the cup plant moth larvae and frequency of leaves infested by the cup plant aphid were obtained by visual estimates for each family row during flowering in each of the three years.

Analyses of variance were performed to determine genetic and environmental effects using the linear models procedure in Statistix 9 [21] and SAS V9.3. All effects were considered to be random [22]. F-tests were performed according to expected mean squares [23]. Intraclass correlations [24] were used to estimate proportions of the total variance due to year, family, and the family x year interaction variance components. Estimates of narrow-sense heritability were determined from ratios of point estimates of variance components [22], as described by Nguyen and Sleper [25]. Standard errors of the estimates of narrow-sense heritability were determined as described by Hallauer and Miranda [26]. Genetic correlation coefficients were estimated utilizing the procedure described by Hallauer and Miranda (1988). The protected least significant difference [22] [26] was used to compare family means within years. Biomass data were analyzed as total dry matter yield from four plants in each single-row plot; whereas, morphological data were analyzed as means from four individual plants from each single-row plot.

\section{Results}

Significant differences were found among years and among families for six agronomic/morphological traits at Brookings. However, the family x year interaction was also significant for those traits (Table 2). Therefore, individual analyses of variance were conducted for each of 2011, 2012 and 2013 (Table 3). The across-years random model analysis of variance (Table 2) was used to determine point estimates of variance components, which were used to calculate intraclass correlations of interest and estimates of narrow-sense heritability for each of the six traits.

Table 2. Mean squares from random model analyses of variance for biomass yield (BY), mass shoot ${ }^{-1}$ (MS), shoots $\mathrm{m}^{-2}$ (SM), plant height (PH), crown area (CA), and internodes shoot ${ }^{-1}$, over a three-year period at Brookings, South Dakota.

\begin{tabular}{cccccccc}
\hline & \multicolumn{7}{c}{ Mean Squares } \\
\hline Source & df & BY & MS & SM & PH & CA & IN \\
Year (Y) & 2 & $924,000,000^{* *}$ & $8983^{* *}$ & $5688^{* *}$ & $23,994^{* *}$ & $22,360,000^{* *}$ & $136^{* *}$ \\
Family (F) & 33 & $5,330,288^{* *}$ & $56^{*}$ & $83^{*}$ & $365^{*}$ & $831,944^{* *}$ & $4^{* *}$ \\
Y $\times$ F & 66 & $1,717,019^{*}$ & $22^{*}$ & $15^{*}$ & $169^{* *}$ & $215,942^{* *}$ & $1^{* *}$ \\
Y $\times$ R & 4 & $3,788,127^{*}$ & $157^{* *}$ & $72^{* *}$ & $588^{* *}$ & $360,293^{* *}$ & $<1$ \\
F $\times$ R & 66 & $1,170,976$ & $19^{*}$ & $35^{* *}$ & 62 & 39,507 & $<1$ \\
\hline
\end{tabular}

*, ** Significant at 0.05 or 0.01 probability level, respectively.

Table 3. Individual-year analyses of variance and annual means and coefficients of variability (CV) for biomass yield for 33 half-sib families and a check population of cup plant at Brookings, South Dakota during 2011 through 2013.

\begin{tabular}{ccccc}
\hline & & \multicolumn{3}{c}{ Mean Squares } \\
\hline Source & df & 2011 & 2012 & 2013 \\
Family & 33 & $1,795,367^{* *}$ & $671,318^{* *}$ & $6,297,640^{*}$ \\
Rep & 2 & $4,524,808$ & 7066 & $1,311,000$ \\
Error & 66 & 194,274 & 21,877 & $3,335,667$ \\
Biomass (kg.ha ${ }^{-1}$ ) & & 6272 & 2183 & 8053 \\
CV (\%) & & 7 & 7 & 23 \\
\hline
\end{tabular}

\footnotetext{
*, ** Significant at the 0.05 or 0.01 level of probability, respectively.
} 
Intraclass correlations revealed that year explained more of the phenotypic variation for all six traits, from a low of $50 \%$ for crown area to a high of $95 \%$ for plant height, than any other source of variation at Brookings (Table 2). For biomass yield, year accounted for $81 \%$ of the phenotypic variation, compared to $5 \%$ for family and $2 \%$ for the family x year interaction (Table 2). Yield was lowest in 2012, being 68\% less than in 2011 and 87\% less than in 2013 (Table 3). The amount of precipitation received during the critical growth period of June through August was 80\% higher in 2011 (225 mm) and 95\% higher in $2013(242 \mathrm{~mm})$ than in $2012(124 \mathrm{~mm})$. Total precipitation during June through August 2012 was less than 50\% of the 30-yr average compared to about 90\% of the 30-year average during 2011 and 2013 (Table 1). Air temperature also varied widely among years, with May through August 2012 being warmer than the same time period during each of 2011 and 2013.

Magnitudes of the difference between means of the highest and lowest families for each of the six traits ranged from 1.4-fold for plant height to 2.4-fold for mass shoot ${ }^{-1}$. Biomass production of the highest yielding families was about twice that of the lowest yielding families in each of the three years at Brookings (Table 4). Families in the uppermost quartile for biomass yield had similar yields in 2011 at Brookings; whereas in 2012, there were four significantly different groups of families within that quartile. In 2013 no differences occurred among families in the two uppermost quartiles (Table 5). Compared to the "check" population, eight families had higher ( $\mathrm{P}<0.05$ ) yields in 2011, 32 had higher yields in 2012, and 20 had higher yields in 2013. The highest yielding family produced $60 \%$ more biomass in 2011, 27\% more biomass in 2012, and 71\% more biomass in 2013 than the lowest yielding family (Table 4). In general, families in the upper quartile for biomass yield were also in the upper quartile for mass shoot ${ }^{-1}$ and plant height.

The contribution of the error mean square (i.e., first-order interaction) to total phenotypic variation was much higher in 2013 than in 2011 and 2012 at Brookings (Table 3). Although mean biomass yield in 2011 was nearly three times that in 2012, CVs were 7\% for both years; whereas, the CV was $23 \%$ for 2013. Rank correlation analysis for families showed moderately strong positive correlations between years 2011 and $2012\left(r=0.67^{* *}\right)$

Table 4. Ranges among family means for biomass (BY), mass shoot ${ }^{-1}$ (MS), shoots $\mathrm{m}^{-2}$ (SM), plant height (PH), crown area (CA), and internodes shoot ${ }^{-1}$ (IS) for 33 half-sib families of cup plant for each of three consecutive years at Brookings, South Dakota.

\begin{tabular}{ccccccc}
\hline Year & BY $\left({\left.\mathrm{kg} \cdot \mathrm{ha}^{-1}\right)}^{-1}\right.$ & MS $(\mathrm{g})$ & SM & PH $(\mathrm{cm})$ & CA $\left(\mathrm{cm}^{2}\right)$ & IS \\
\hline 2011 & $4686-7507^{* *}$ & $13.6-31.3^{* *}$ & $20-30^{* *}$ & $147-195^{* *}$ & $2101-3647^{* *}$ & $6-10^{* *}$ \\
2012 & $1510-3421^{* *}$ & $4.7-11.1^{* *}$ & $24-33^{* *}$ & $62-88^{* *}$ & $1179-2410^{* *}$ & $4-7^{* *}$ \\
2013 & $5184-10475^{*}$ & $11.0-27.5^{* *}$ & $33-50^{* *}$ & $106-142^{* *}$ & $1585-2539^{* *}$ & $5-9^{* *}$ \\
\hline
\end{tabular}

${ }^{* * *}$ Difference among family means significant at the 0.05 or 0.01 level of probability, respectively.

Table 5. Families in the uppermost quartile for biomass yield for 33 half-sib families of cup plant in each of three consecutive years at Brookings, South Dakota.

\begin{tabular}{|c|c|c|c|c|c|}
\hline \multicolumn{2}{|c|}{$\underline{2011}$} & \multicolumn{2}{|c|}{$\underline{2012}$} & \multicolumn{2}{|c|}{$\underline{2013}$} \\
\hline Family $^{\#}$ & $\mathrm{~kg} \cdot \mathrm{ha}^{-1}$ & Family ${ }^{\#}$ & $\mathrm{~kg} \cdot \mathrm{ha}^{-1}$ & Family $^{\#}$ & $\mathrm{~kg} \cdot \mathrm{ha}^{-1}$ \\
\hline 18 & 7507 & 3 & 3421 & 31 & 10,475 \\
\hline 3 & 7498 & 11 & 3092 & 5 & 10,464 \\
\hline 7 & 7218 & 7 & 3066 & 7 & 10,016 \\
\hline 23 & 7182 & 23 & 3010 & 12 & 9973 \\
\hline 31 & 7138 & 18 & 3008 & 30 & 9664 \\
\hline 10 & 6966 & 31 & 2741 & 23 & 9600 \\
\hline 5 & 6921 & 5 & 2641 & 9 & 9216 \\
\hline 24 & 6741 & 10 & 2326 & 13 & 9195 \\
\hline LSD (0.05) & 718 & & 241 & & 2977 \\
\hline
\end{tabular}


and 2012 and $2013\left(0.62^{* *}\right)$. Families with the highest mean rank for biomass, averaged across years, were F7 (mean rank = 3.0/33), F23 (mean rank = 4.7/33), and F3 (mean rank = 5.0/33) (Table 5). Families 31, 7, 5, 23, 11 and 3 had high biomass yields and desirable expression for biomass-related morphological traits in each year, as well as averaged across years (Table 5).

Families F7 and F31 ranked consistently high for mass shoot ${ }^{-1}\left(22 \mathrm{~g} \cdot \mathrm{shoot}^{-1}\right)$ and crown area $\left(2510 \mathrm{~cm}^{2}\right)$ in all three years and were ranked as the top two families for biomass yield averaged across three years at Brookings (Table 4 and Table 5). For shoots $\mathrm{m}^{-2}$, families F12 and F22 were consistently high (37 shoots $\mathrm{m}^{-2}$ ) in each of the three years, whereas F2 and F29 were consistently low $\left(26\right.$ shoots $\left.\mathrm{m}^{-2}\right)$. F22 was the lowest yielding family, averaged across years, and both F2 and F29 ranked in the bottom 20\% for biomass yield averaged across years (data not shown). Families F23 and F31 ranked consistently high for plant height and were among the five highest ranking families for biomass yield averaged across years (Table 5).

Significant family and family x year effects (ANOVA not shown) were detected for biomass at Arlington. Therefore, separate analyses of variance were also conducted for each year. Significant differences were found among families in each of the three years at Arlington (Table 6). Averaged across years, biomass for the uppermost quartile of families ranged from $9504 \mathrm{~kg} \cdot \mathrm{ha}^{-1}$ to $11,269 \mathrm{~kg} \cdot \mathrm{ha}^{-1}$, and those families produced, on average, 43\% more biomass than the mean of the lowest quartile of families. Families F11 and F30 were in the uppermost quartile in all three years, and F11was the top-ranked family averaged across years (data not shown). F11 was also in the uppermost quartile for biomass yield, averaged across years, at Brookings. No significant difference was found among years for biomass production at Arlington (Table 6). The hybrid population developed by K. Albrecht from a cross between natural populations from Wisconsin and Arkansas produced 35\% more biomass $\left(15,144 \mathrm{~kg} \cdot \mathrm{ha}^{-1}\right)$, averaged across years, than the highest yielding half-sib family at Arlington. It also produced the highest mean yield (i.e., $24,510 \mathrm{~kg} \cdot \mathrm{ha}^{-1}$ in 2013) for any entry at any location during any year at Arlington.

At Brookings, significant positive genetic correlations were found between biomass yield and mass shoot ${ }^{-1}$, plant height, crown area, and internodes shoot ${ }^{-1}$. Mass shoot ${ }^{-1}$ had a significant negative correlation with shoots $\mathrm{m}^{-2}$ but had positive correlations with plant height, crown area, and internodes shoot ${ }^{-1}$. Plant height showed significant positive correlations with mass shoot ${ }^{-1}$, crown area and internodes shoot ${ }^{-1}$. A positive correlation was also detected between crown area and internodes shoot ${ }^{-1}$ (Table 7).

Heritability estimates were moderate and similar in magnitude for biomass yield, mass shoot ${ }^{-1}$, shoots $\mathrm{m}^{-2}$, plant height, crown area, and internodes shoot ${ }^{-1}$ at Brookings (Table 8). In comparison, the estimate of nar-

Table 6. Annual means and coefficients of variability (CV) and ranges in family means for biomass yield ( $\left.\mathrm{kg} \cdot \mathrm{ha}^{-1}\right)$ for cup plant for each of three consecutive years at Arlington, Wisconsin.

\begin{tabular}{cccc}
\hline Year & Annual mean & CV (\%) & Range in family means \\
\hline 2011 & 8650 & 21.5 & $5983-11,589^{*}$ \\
2012 & 8665 & 14.8 & $7062-11,011^{*}$ \\
2013 & 8588 & 25.4 & $5108-13234^{* *}$ \\
\hline
\end{tabular}

*, ** Difference among family means significant at the 0.05 or 0.01 level of probability, respectively.

Table 7. Genetic correlations among biomass yield (BY), mass shoot ${ }^{-1}$ (MS), shoots $\mathrm{m}^{-2}$ (SM), plant height (PH), crown area (CA), and internodes shoot ${ }^{-1}$ for cup plant at Brookings, South Dakota during 2011 through 2013.

\begin{tabular}{cccccc}
\hline Trait/Trait & BY & MS & SM & PH & \\
\hline MS & $0.75^{* *}$ & & & \\
SM & $0.21^{*}$ & $-0.58^{* *}$ & & \\
PH & $0.75^{* *}$ & $0.69^{* *}$ & -0.07 & $0.74^{* *}$ & $0.68^{* *}$ \\
CA & $0.72^{* *}$ & $0.42^{* *}$ & $0.41^{* *}$ & $0.70^{* *}$ & 0.12 \\
IS & $0.76^{* *}$ & $0.75^{* *}$ & -0.12 & \\
\hline
\end{tabular}

\footnotetext{
${ }^{*},{ }^{* *}$ Significant at the 0.05 or 0.01 level of probability, respectively.
} 
Table 8. Estimates of narrow-sense heritability and their standard errors (in parentheses) for biomass yield and related morphological traits during 2011 through 2013 at Brookings, South Dakota.

\begin{tabular}{cc}
\hline Trait & Narrow-sense heritability \\
\hline Biomass yield & $0.65(0.17)$ \\
Mass shoot $^{-1}$ & $0.56(0.23)$ \\
Shoots ${ }^{-2}$ & $0.63(0.19)$ \\
Plant height & $0.52(0.26)$ \\
Crown area & $0.72(0.24)$ \\
Internodes shoot ${ }^{-1}$ & $0.67(0.26)$ \\
\hline
\end{tabular}

row-sense heritability for biomass yield (the only trait measured at Arlington) was 0.24 at Arlington, which was substantially lower than the heritability estimate (0.65) for biomass yield at Brookings. Compared to Brookings, the among-family component of variance composed a relatively smaller fraction of the total phenotypic variance, as indicated by the significance $(\mathrm{P}=0.05)$ of the F-ratio for differences among family means from the analyses of variance in 2011 and 2012 at Arlington (Table 6). Correspondingly, CVs for biomass yield were three times larger at Arlington than at Brookings in 2011 and 2012; whereas, CVs were similar for both locations in 2013 (Table 3 and Table 6).

The simple linear correlation coefficient between family means for biomass yield at Brookings and Arlington was $-0.20(P=0.23)$. This indicated inconsistency in rank of families for biomass production between the two locations. April through August precipitation at Arlington in 2012 was 55\% and 48\% of that received during the same time periods in 2011 and 2013, respectively. However, the drought at Arlington in 2012 did not impact biomass production (i.e., no significant difference among years) compared to the strong negative effect of drought of similar magnitude during the same time period at Brookings. Biomass production at Arlington in $2012\left(8665 \mathrm{~kg} \cdot \mathrm{ha}^{-1}\right.$ ) was $98 \%$ of that produced in each of 2011 and 2013 at that location.

Larvae of the cup plant moth (Eucosma giganteana Riley) indiscriminately destroyed $>90 \%$ of vegetative and floral meristems in all families during 2012 at Brookings. In contrast, $<5 \%$ of the meristems were infested in each of 2011 and 2013. The significant reduction in internodes shoot ${ }^{-1}$ in 2012 (Table 4) is a direct effect of the high frequency of meristem destruction by larvae of the cup plant moth.

Sporadic occurrence of an aphid [Uroleucon rudbeckiae (Fitch)] was observed during mid-July to early August 2013 at Brookings. Although $<10 \%$ of the plants were infested, aphid-infested plants usually had multiple infested leaves, which were predominantly young leaves from the uppermost two or three nodes. Infested leaves often supported $>300$ aphids that usually fed for up to 10 days. No aphids were observed during 2011 or 2012. A parasitic wasp (Acanthocaudus tissotti Smith) (Hymenoptera: Braconidae) parasitized $>75 \%$ of the aphids in 2013.

No serious incidence of leaf or stem disease was observed during the duration of the study at either location. Also, incidence of lodged shoots was low at both locations. The low frequency of lodged shoots across three years at both locations in transplanted rows (Brookings) and a spaced planting (Arlington) suggested lodging is not likely to be a serious problem in this population.

\section{Discussion}

Cup plant, although indigenous to only North America, is receiving global attention for its current or potential use for forage, bioenergy, biodiversity, conservation, and phytoremediation. Obviously, with those agronomical and ecologically broad current and potential functions, breeding for improvements in biomass and other traits is of interest on several continents. For example, Franzing et al. [13] evaluated six accessions (two of which were provided by one of us, K.A. Albrecht, and the origins of the other four were unknown) of cup plant in Germany and found large among-population differences for biomass plant ${ }^{-1}$ and forage quality. They also pointed out that, because of its high water use efficiency and suitability for low input agricultural systems, cup plant will become more important in Europe in the future for bioenergy production on marginal lands. Finding natural sources of genetic variation or creating genetic variation through controlled pollinations for specific agricultural, industrial, 
or ecological purposes will become important components of improvement programs in diverse environments at a global level.

To date only a few natural populations of cup plant from the northern Great Plains and Midwest have been collected and evaluated, primarily in Wisconsin. The wide latitudinal and longitudinal range of cup plant in North America north of Mexico suggests substantial ecotypic variation for biomass production and other traits related to its potential for bioenergy and ecological purposes. This is borne out by previous preliminary evaluations in Wisconsin [5]. The superior biomass production of the Wisconsin ecotype $\mathrm{x}$ Arkansas ecotype cross at Arlington suggested moving natural populations north may provide an avenue for increasing biomass production in areas where indigenous populations are restricted for biomass production by their inability to utilize the latter one third of the growing season due to flowering date, as pointed out by Casler [15] for switchgrass. Therefore, widespread germplasm collection throughout its natural range, as is customarily done when breeding programs are initiated for wide-ranging native species with little or no previous artificial selection for agronomic and/or environmental uses, should be a high priority for developing successful among- and within-population selection programs for cup plant wherever it has been shown to be well adapted worldwide.

Temporal variation for precipitation and temperature undoubtedly contributed to large variation among years for biomass production and related morphological traits at Brookings. Low biomass production in 2012 could be attributed, in part, to prolonged drought and high temperature during the middle of the growing season. However, in addition to drought stress, larvae of the cup plant moth destroyed $>75 \%$ of the terminal meristems and reduced number of internodes shoot ${ }^{-1}$ and size of inflorescences in 2012. In contrast, in 2011 and 2013 higher biomass yields were in response to greater amounts of precipitation and lower frequency $(<5 \%)$ of meristem predation. High biomass production again in 2013 when precipitation was near normal indicated a resiliency that enabled cup plant to strongly recover from drought and insect related stresses during 2012, as demonstrated by 100\% plant survival from October 2011 through October 2013.

Fifty percent more biomass production, averaged across years and families, at Arlington than at Brookings revealed phenotypic plasticity in this population in response to variation in growing conditions. In particular, at Arlington higher soil moisture levels during drought in 2012 allowed all families to achieve a greater level of their biomass yield potentials, compared to Brookings. Biomass production at Arlington during drought comparable to the two bracketing years with normal precipitation was likely due to landscape position, soil type, and hydrology. The experimental site maintained a high water table from which the deep-rooted cup plant accessed sufficient water for normal growth during the droughty growing season of 2012.

However, plant spacing also varied between locations, with $0.4 \mathrm{~m}^{2}$ plant ${ }^{-1}$ at Brookings compared to $1.0 \mathrm{~m}^{2}$ plant $^{-1}$ at Arlington. The optimum plant density for cup plant grown for bioenergy is unknown. In this study, the $1.0 \mathrm{~m}^{2}$ and the $0.4 \mathrm{~m}^{2}$ space allocations for individual plants at Arlington and Brookings were used because of high biomass production from those spacing in previous experiments at the respective locations [5]. In Europe, experiments to determine optimum plant density for biomass production from transplanted stands have been inconclusive, with $0.25 \mathrm{~m}^{2}$ and $0.38 \mathrm{~m}^{2}$ space allocations for individual plants producing similar biomass yields in the second and subsequent production years [8].

The cup plant moth presently poses the most serious biotic threat to biomass and seed production of cup plant in the northern Great Plains. This species has the ability to essentially stop growth and biomass accumulation by reducing the number of phytomers produced by each shoot by up to $50 \%$. The reason for the sporadic nature of the level of infestation from year to year is unknown. In this study, in only one out of three years was the damage sufficient to cause major losses in biomass. The cup plant aphid also exhibited sporadic occurrence, being present at Brookings in 2013 but not in 2011 or 2012. Since it is a piercing-sucking insect, the impact of its feeding, with or without mortality due to parasitism by Acanthocaudus tissotti, on biomass was difficult to ascertain.

Little information exists on quantitative genetics of biomass and related traits in perennial dicotyledonous plants, with the exception of alfalfa (Medicago sativa L.) (e.g., [18] [27] [28] which have been identified as potential herbaceous bioenergy crops). Estimates of narrow-sense heritability for biomass and related traits are not available for perennial species in the Asteraceae. However, Alza and Fernandez-Martinez [29] found a range in narrow-sense heritability estimates from 0.55 to 0.79 among six dryland and irrigated environments for biomass of annual sunflower (Helianthus annuus L.) in southern Spain.

Estimates of narrow-sense heritability from transplanted single-row plots of cup plant at Brookings indicated moderate levels of within-population genetic variation for biomass yield and five morphological traits. Eight out 
of the nine highest biomass families (i.e., upper quartile) were common to 2011 and 2012. However, only four families were in the upper quartile for biomass yield in 2012 and 2013. Those four families presumably have value in a breeding program because of resiliency that enabled them to produce relatively high amounts of biomass under drought- and insect-related stresses and to respond with high biomass production $\left(>10,000 \mathrm{~kg} \cdot \mathrm{ha}^{-1}\right)$ during the near-normal precipitation year following the stresses.

Narrow-sense heritability (0.65), based on three years at Brookings, suggested biomass yield could be improved by selecting among families for yield per se. For example, if among family selection was employed at a $15 \%$ selection intensity (i.e., select the 5 highest yielding families) the expected gain in biomass yield would be $760 \mathrm{~kg} \cdot \mathrm{ha}^{-1}$ per cycle of selection. The difference in size of estimates of narrow-sense heritability for biomass at Brookings and Arlington is demonstrative of the fact that heritability is not only a property of the population but also of the environment to which the plants are subjected [30]. Heritability estimates are useful for the environment where the evaluation occurred. Thus, progress from selection for biomass would be expected to be slower in the high yield equidistant spaced plant environment at Arlington compared to the low yield environment at Brookings with different intra- and inter-row spacing. Lower narrow-sense heritability at Arlington was due to larger family $\times$ year and family $\mathrm{x}$ replication variances and decreased additive genetic variance relative to Brookings [31].

The heritability estimates for biomass and related traits for cup plant at Brookings are at the high end of ranges reported for other perennial forage and biofuel species (e.g., [32] [33]) and are the first of their kind for a native perennial forb with no previous artificial selection for biomass or other agronomic traits. These estimates could be inflated due to the failure to remove the family $\mathrm{x}$ location interaction from the estimate of additive genetic variance in the heritability formula [34]. Based on strong additive genetic correlations between biomass and mass shoot ${ }^{-1}$, plant height, crown area, and internodes shoot ${ }^{-1}$, indirect selection for any of those traits may also be effective. Since data were collected on an individual plant basis for the morphological traits, amongfamily selection for biomass yield accompanied by within-family selection for a genetically correlated morphological trait would be expected to provide faster progress than among-family selection alone [20]. Strong genotypic correlations of biomass yield with mass shoot ${ }^{-1}$ and plant height were consistent with results reported by Sahai et al. ([35]) for cowpea [Vigna unguiculata (L.)].

Since cup plant is a diploid, quantitative genetic theory for half-sib family populations in diploids is appropriate for developing selection schemes [36]. Based on the results of the present study, among-family selection or among- and within family selection would be expected to result in increases in biomass yield and positive expression of the five morphological traits [20]. At both locations, stands were still nearly $100 \%$ and individual plants within family rows were still discernible as of summer 2014, so selecting best individuals (based on morphological characteristics that have positive additive genetic correlations with yield) from the highest yielding families (i.e., within family selection) would be possible from four-year-old stands [20].

Only one family was common to either the upper or lower quartile for biomass production at both locations, indicating among-and-within-family selection for improving biomass production in this population should be done separately at each location. Also, since the five morphological characters were measured only at Brookings, the choice of which of those to utilize for within-family selection would be appropriate for Brookings only. Of the five morphological traits, mass shoot ${ }^{-1}$, plant height, and internodes shoot ${ }^{-1}$ had similar positive genetic correlations with biomass yield and similar moderate narrow-sense heritability, as well. Therefore, any of those three would be expected to be useful for selecting individual plants within families with high biomass plot yield [20].

The temporal variation in annual precipitation, which influenced growing conditions during the 3-year evaluation period, provided an opportunity to consider different selection strategies for improving biomass in this population of cup plant. Two of the years (2011 and 2013) had near normal precipitation, whereas precipitation during 2012 was well below normal. If this ratio of non-stress to stressful annual environmental conditions was to be considered typical for the area of intended use, choosing a selection strategy could be based on the genetic variance expressed under stress conditions. Since the genetic variance under stress conditions (i.e., 2012) was not exceedingly greater than under non-stress conditions (i.e., 2011 and 2013) selection for mean productivity across years would be the most likely strategy to improve mean yield in both stress and non-stress environments [37] in this population.

In summary, this study showed that variation in environmental conditions among years played the most important role in phenotypic traits in multi-family cup plant trials. However, families also had a major role in de- 
termining variation for investigated traits. Though family $\times$ year interaction effects were significant, most topyielding cup plant families showed consistent yield potential, indicating that selection for biomass based on the family means in a single environment could be successful. This conclusion was corroborated by the rank correlation analysis between years. Due to the diverse weather conditions, our results also provided some important genetic information to consider when selecting cup plant cultivars adapted to drought conditions.

\section{Acknowledgements}

This research was supported by funding from the North Central Regional Sun Grant Center at South Dakota State University through a grant provided by the US Department of Energy Bioenergy Technologies Office under award number DE-FG36-08G088073. It is also partially supported by USDA-NIFA Hatch project 1005459. We express appreciation to Dr. Robert Kula, USDA-ARS Systematic Entomology Laboratory, Washington DC for identification of Acanthocaudus tissotti.

\section{References}

[1] Barkley, T.M. (1986) Asteraceae. Great Plains Flora Association, Flora of the Great Plains. University Press of Kansas, Lawrence, 839-1021.

[2] Johnson, J.R. and Larson, G.E. (1999) Grassland Plants of South Dakota and the Northern Great Plains.

[3] Stanford, G. (1990) Silphium perfoliatum (Cup-Plant) as a New Forage. Conference August 5-9, 1990 Conference Year, Cedar Falls, 33-37.

[4] Van Bruggen, T. (1976) The Vascular Plants of South Dakota. The Iowa State University Press, Ames.

[5] Albrecht, K.A. and Goldstein, W. (1997) Silphium perfoliatum: A North American Prairie Plant with Potential as A Forage Crop. Conference June 8-19 Conference Year, Winnipeg, 167-168.

[6] Lehmkuhler, J.W., Ramos, M.H. and Albrecht, K.A. (2007) Cup-Plant Silage as a Replacement for Corn Silage in Growing Beef Cattle Diets. Forage and Grazinglands.

[7] Pichard, G. (2012) Management, Production, and Nutritional Characteristics of Cup-Plant (Silphium perfoliatum) in Temperate Climates of Southern Chile. Cienciae Investigación Agraria, 39, 61-77.

[8] Gansberger, M., Montgomery, L.F.R. and Liebhard, P. (2015) Botanical Characteristics, Crop Management and Potential of Silphium perfoliatum L. as a Renewable Resource for Biogas Production: A Review. Industrial Crops and Products. Industrial Crops and Products, 63, 362-372.

[9] Frączek, J., Mudryk, K. and Wróbel, M. (2011) Cup plant Silphium perfoliatum L. Biomass Source for Biofuel Production. Inżynieria Rolnicza, 131, 21-27.

[10] Pichard, G., Cussen, R. and Moore, F. (1997) Productivity of Silphium perfoliatum L. in Low Input Agricultural Systems. Conference June 8-19, 1997 Conference Year, Winnipeg, 22-103-122-104.

[11] Pan, G., Ouyang, Z., Luo, Q., Yu, Q. and Wang, J. (2011) Water Use Patterns of Forage Cultivars in the North China Plain. International Journal of Plant Production, 5, 181-194.

[12] Zhang, X.F., Xia, H.P., Li, Z.A., Zhuang, P. and Gao, B. (2010) Potential of Four Forage Grasses in Remediation of Cd and Zn Contaminated Soils. Bioresource Technology, 101, 2063-2066. http://dx.doi.org/10.1016/j.biortech.2009.11.065

[13] Franzaring, J., Schmid, I., Bauerle, L., Gensheimer, G. and Fangmeier, A. (2014) Investigations on Plant Functional Traits, Epidermal Structures and the Ecophysiology of the Novel Bioenergy Species Sida hermaphrodita Rusby and Silphium perfoliatum L. Journal of Applied Botany and Food Quality, 87, 36-45.

[14] Voigt, T., Lee, D.K. and Kling, G.J. (2012) Perennial Herbaceous Crops with Potential for Biofuel Production in the Temperate Regions of the USA. CAB Reviews, 7, 1-13. http://dx.doi.org/10.1079/PAVSNNR20127015

[15] Casler, M.D. (2012) Switchgrass Breeding, Genetics, and Genomics. In: Monti, A., Ed., Switchgrass: A Valuable Biomass Crop for Energy, Springer-Verlag, London, 29-54. http://dx.doi.org/10.1007/978-1-4471-2903-5_2

[16] Boe, A., Springer, T., Lee, D.K., Rayburn, A.L. and Gonzalez-Hernandez, J. (2013) Underutilized Grasses. In: Saha, M.C., Bhandhari, H.S. and Bouton, J.H. Eds., Bioenergy Feedstocks: Breeding and Genetics, Wiley-Blackwell, Hoboken, 173-205. http://dx.doi.org/10.1002/9781118609477.ch9

[17] Dwiyanti, M.S., Stewart, J.R. and Yamada, T. (2013) Germplasm Resources of Miscanthus and Their Application in Breeding. In: Saha, M.C., Bhandari, H.S. and Bouton, J.H., Eds., Bioenergy Feedstocks: Breeding and Genetics, John Wiley \& Sons, Inc., Oxford, 49-66.

[18] Bhattari, K., Brummer, E.C. and Monteros, M.J. (2013) Alfalfa as a Bioenergy Crop. In: Saha, M.C., Bhandhari, H.S. 
and Bouton, J.H., Eds., Bioenergy Feedstocks: Breeding and Genetics, Wiley-Blackwell, Hoboken, 207-231. http://dx.doi.org/10.1002/9781118609477.ch10

[19] Boe, A., Albrecht, K., Johnson, P.J., Owens, V., Mamo, T. and Yang, C. (2012). Quantitative Genetic Analysis of Biomass Yield, Pest Resistance, and Other Agronomic Traits in Prairie Cordgrass and Cup Plant. http://sungrant.tennessee.edu/NR/rdonlyres/40B6A4BE-C9A0-4A32-BBD0-8D5A2CF0D436/3690/16Boe Arvid.pdf

[20] Casler, M.D. and Brummer, E.C. (2008) Theoretical Expected Genetic Gains for Among-and-Within-Family Selection Methods in Perennial Forage Crops. Crop Science, 48, 890-902. http://dx.doi.org/10.2135/cropsci2007.09.0499

[21] Statistix (2009) Statistix 9: Analytical Software Tallahassee, FL.

[22] Kuehl, R.O. (1999) Design of Experiments: Statistical Principles of Research Design and Analysis. Duxbury Press, Pacific Grove.

[23] Satterthwaite, F.E. (1946) An Approximate Distribution of Estimates of Variance Components. Biometrics, 2, 110-114. http://dx.doi.org/10.2307/3002019

[24] Kempthorne, O. (1957) An Introduction to Genetic Statistics. John Wiley \& Sons, Inc., New York.

[25] Nguyen, H.T. and Sleper, D.A. (1983) Theory and Application of Half-Sib Mating in Forage Grass Breeding. Theoretical and Applied Genetics, 64, 187-196. http://dx.doi.org/10.1007/BF00303763

[26] Hallauer, A.R. and Miranda, J.B. (1988) Quantitative Genetics in Maize Breeding. Iowa State University Press, Ames.

[27] Kehr, W.R. and Gardner, C.O. (1960) Genetic Variability in Ranger Alfalfa. Agronomy Journal, 52, 41-44. http://dx.doi.org/10.2134/agronj1960.00021962005200010013x

[28] Dudley, J.W., Busbice, T.H. and Levings, C.S. (1969) Estimates of Genetic Variance in “Cherokee” Alfalfa (Medicago sativa L.). Crop Science, 9, 228-231. http://dx.doi.org/10.2135/cropsci1969.0011183X000900020036x

[29] Alza, J.O. and Fernandez Martinez, J.M. (1997) Genetic Analysis of Yield and Related Traits in Sunflower (Helianthus annuus L) in Dryland and Irrigated Environments. Euphytica, 95, 243-251. http://dx.doi.org/10.1023/A:1003056500991

[30] Falconer, D.S. and Mackay, T.F.C. (1996) Introduction to Quantitative Genetics. Longman Group Ltd., Edinburgh Gate.

[31] Conner, J.K., Franks, R. and Stewart, C. (2003) Expression of Additive Genetic Variances and Covariances for Wild Radish Floral Traits: Comparison between Field and Greenhouse Environments. Evolution, 57, 487-495. http://dx.doi.org/10.1111/j.0014-3820.2003.tb01540.x

[32] Boe, A. and Lee, D.K. (2007) Genetic Variation for Biomass Production in Prairie Cordgrass and Switchgrass. Crop Science, 47, 929-934. http://dx.doi.org/10.2135/cropsci2006.05.0323

[33] Rose, L.W., Das, M.K. and Taliaferro, C.M. (2008) Estimation of Genetic Variability and Heritability for Biofuel Feedstock Yield in Several Populations of Switchgrass. Annals of Applied Biology, 152, 11-17. http://dx.doi.org/10.1111/j.1744-7348.2007.00186.x

[34] Johnson, H.W., Robinson, H.F. and Comstock, R.E. (1955) Estimates of Genetic and Environmental Variability in Soybeans. Agronomy Journal, 47, 314-318. http://dx.doi.org/10.2134/agronj1955.00021962004700070009x

[35] Sahai, G., Malaviya, D.R. and Singh, U.P. (2013) Morphological Traits Association with Fodder and Seed Yield in Vigna unguiculata (L.). Journal of Environmental Biology, 34, 139-145.

[36] Nyquist, W.E. (1991) Estimation of Heritability and Prediction of Selection Response in Plant Populations. Critical Reviews in Plant Science, 10, 235-322. http://dx.doi.org/10.1080/07352689109382313

[37] Rosielle, A.A. and Hamblin, J. (1981) Theoretical Aspects of Selection for Yield in Stress and Non-Stress Environment. Crop Science, 21, 943-946. http://dx.doi.org/10.2135/cropsci1981.0011183X002100060033x 